\title{
Staff Readiness to Change in Sungai Petani Community College Organization: a Pls-Sem Approach.
}

\author{
Najmiah Bt. Hj. Abdullah', Reezlin Bin Abd Rahman², Abd Latif B. Ahmad ${ }^{3}$ \\ Sungai Petani Community College, Kedah.
}

\begin{abstract}
Changes in the organization will take place when there is an objective change, direction and exchange of new management within an organization. The purpose of this study is to find the best approach to be used by the management in selecting the most contributing factors to stimulate the staff's attitude for their readiness to change. Several contributing factors such as management and administration, organizational commitment and influence of peer group are seen as catalysts for staff readiness in Sungai Petani Community College (SPCC) to change. The research model was proposed with three hypotheses in responding the objective of the study. This quantitative study involves 74 respondents comprising staffs in the Sungai Petani Community College who are required to answer a set of questionnaires. This study uses descriptive statistical analysis using the SPSS version 21 software while the inferential statistics are used Partial Least Squares Structural Equation Modelling (PLS-SEM) version 3.0. The findings show that Influence of peer group factor has a positive impact on employee willingness in SPCC to change while management and administration factors as well as organizational commitment have a little significant effect on their willingness to change. The results of this study can help the management to use the stimulus factors that will help the organization in implementing the changes in the organization later.
\end{abstract}

Keywords: Change Management, Management and Administration, Organizational Commitment, Influence of Peer Group, and Readiness to Change.

\subsection{Introduction}

Organizational changes are not exempt from the change of objective which linked to the effectiveness and success of the organizational [1].These changes involve system changes, working environments, procedures and relationships involving status quo [2]. It has undoubtedly affected all employees in the organization and demand changes that take time to implement and practice and will face some of the conflicts [3]. All of the conflicts require organizational management creativity to handle, manage and minimize in order to be able to achieve the objectives [4].

Positive organizational change demands the commitment of the employees to co-operate in order to achieve the organization's goals. Employees' willingness to change involves readiness of the attitude based on what are the consequences they can get from their willingness to change [5].The acceptance for changes will be acknowledged when employees know the factors and the importance of these changes to them [6].

In the organization aspect, [7] emphasized that in implementing the management initiative to make a change in the organization, it is a challenging task to deal with individual or employee who each have a unique life experience, multiple levels of knowledge, attitudes, values, the pattern of life and the level of self-motivation. Due to that, the organization need to plan, arrange and manage the changes systematically that parallel with employees' needs such as promotion and criteria of excellence [8]. 


\subsection{Problem Statement}

Sungai Petani Community College, which is one of a skills-based institutions also involved with the new organizational changes which aim to enhance organizational objectives, capabilities and it functions to the communities. The changes will certainly involve a new paradigm and approaches that demand the willingness of its employees to change. In implementing the changes in the organization, the management needs to figure out some of the best approach to implement the transformation to the staff. Organizational approaches that need to be apply should be appropriate and has been identified as the main causes of changes to the staff. The results of this study can help the management of the Sungai Petani Community College in looking at which stimulus factors or approaches that are most effective as agent of changes in order to the organization changes can be implemented smoothly and systematically. With that, the objective of this study is to identifying variables or contributing factors on the readiness to change among staff at the Sungai Petani Community College.

[9] stated that the stimuli to change is much influenced by employee relationships with management, knowledge on job task, acquired skills and job responsibility. Meanwhile, [10] lists the dominant factors in his theory of management changes of as 1). Culture and organizational management; 2). Urgent task; and 3). Influence of Peer group. Based on this two statements, the management of Sungai Petani Community College decided to propose the three contributing factors that stimulate the staff to change which are administrative management factors, organizational commitment and the influence of the peer group.

\subsection{Literature Review}

\subsection{Change Management}

Change Management from organizational perspective is a process where by a new system are implemented in a controlled manner according to the defined framework [8].Meanwhile [6] defines it as a form of leadership and direction towards organizational transformation processes, especially those relating to humanitarian aspects and how to deal with resistance to change. [11] noted that managing these changes involves the identification and practice of new values, attitudes, norms, and behaviours within the organization that support new ways of doing work and addressing the resistance to change. It is a process that involves several social activities in the management, implementation and guided approach in achieving a goal that leads to the success of an organization. In order to manage these activities systematically, change agents need to be created so that the journey to change will be clearly defined and objective.

Change agents are responsible for establishing, delivering and building commitments towards the vision and mission desired by the organization [12] .It can be individual or a team, which serves to mobilize and catalyse any planned changes. Change agent used communication and interactions as their strategic tool for achieving or delivering the purpose of changing in organization [13]. He stated that the role of the agent is as a) to develop a need for change; b) to establish an information exchange relationship; c) to diagnose problems; d) to create an intent in the client to change and; d) to translate an intent to action. In other word, change agent will attempt to help other employees in order to jointly receive the new changes and strive together to achieve organisational change.

\subsection{Management and Administrative}

In the study by [14], they found that the practice of admin and management in organizations helped to adapt to change management and to enhance organizational excellence. This also supported by the [15], that studied on comparing the effectiveness of management and administration with the quality of communication and the relationship with organizational change, which found that administration contributed greatly to the success of the implementation of change. The above statements also supported with the 
findings from [16] which contended that there is a significant positive relationship between strategic leadership practice and the level of readiness of organization change. They insisted that each level of management and operations in the organization should be given strategically task and focus to achieve the implementation of change strategies.

\subsection{Organizational Commitment}

Commitment is closely related to emotional feelings, ideas, philosophies and values held or internalized by an individual when performing tasks [17]. Feelings of responsibility, involvement, loyalty and feeling of ownership are characteristics that nurture the individual to be committed in their work task [18]. Hence, commitment is extremely related to the individual psychological context and internal motivation to inculcate individual involvement with the organization's goal, philosophies and objectives.

Organizational commitment is defined as a psychological construct that involves some positive characteristics in staff belief which create the relation with the organization and has implications for the individual's decision to continue working in the organization. [19] augmented that staff with high organizational commitment are more likely to excel in his career compared to staff who have no organizational commitment. [20] stated that organizational commitment is a connection between goals with personal mission, organizational mission, and individual personal beliefs regards to the mission, attitude and loyalty to the organization and the results that to be achieved. They also insisted that achievement of organizational goals depends on the commitment of members in the organization to work on it. [21]. stated that there is a positive relationship between transformational leadership, organizational commitment and professional satisfaction.

\subsection{The influence of Peer group}

Influence by a peer group play a role in influencing an individual either willing to change or not. The paradigm of organization sometimes distinguished by various interpretations and meanings that involve some of the blurred information, misunderstandings and bad thoughts from the staff. [8] contended that the rejection or acceptance of a changes often occurs when there is a clash or similarity of two or more opinions issued through different knowledge, experiences and situations between staff. In addressing the situation, the organizational approaches need to be more emphasized in influence organizational staff from the aspect of mental, emotional and physical [22] and also must ensure all staffs can influence each other in career development [8]. Staff will always need views and opinions from other people, especially those close to them. It is therefore very important to have peer group who are able to help others with the new changes in organization. With various valuable experience and knowledge came from the peer groups, it can benefit the employees and organizations [23]. Each employee has a different experience that can be shared and various ideas and creative thinking can be manifested.

\subsection{Sungai Petani Community College}

The Sungai Petani Community College is under the Ministry of Higher Education Malaysia. This organization is a skill-based public institution under government of Malaysia. Course offered in this institution are the Certificate level of Culinary, Hotel Operation, Pastry, Beauty and SPA and Automotive. Like other colleges, Sungai Petani Community College also facing the changes in management due to the changes in strategic planning or management. These changes are seen as a positive effort in increasing the function of the organization's goal and objectives to students, communities and countries. It is a challenge for management to implement the changes or reorganize strategies according to the objective changes togetherness with their staffs. The management need to find the best approach for them to formulate the strategies and implementing it to their staff. 


\subsection{Model and Hypothesis of Study}

Hypothesis model is proposed based from the literature review. Outer factor or independent variable for this study is management and administration, organizational commitment and influence of peer group. While Inner factor or dependant variable is readiness to change. The proposed model of this study is illustrated in Diagram 1 below.

Based on the proposed Model below, the hypothesis of the study were formed to see whether these factors are contributing to the readiness of employees to change. The research hypothesis are as follows:

H1: Management and administration has a significant impact on employee readiness to change

H2: Organizational commitment has a significant impact on employee readiness to change

H3: Peer group interaction has a significant impact on employee readiness to change

These hypotheses involve statistical tests which definitely undergo the procedures and assessment standards contained in the research methodology.

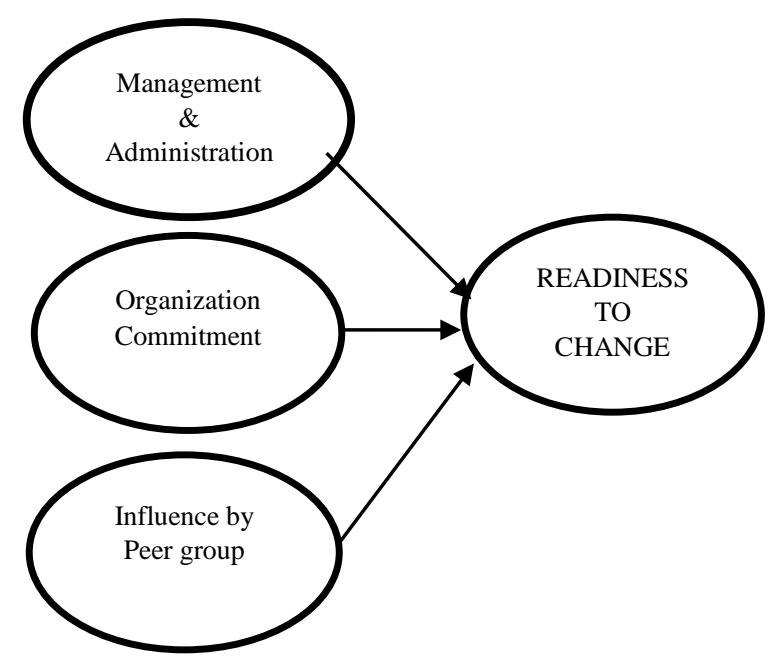

Diagram 1: Proposed Hypothesis Model

\subsection{Research Methodology}

This is quantitative approach study that survey on the employee readiness to change which used cross sectional data collection. While the unit analysis is focused on the all staffs at the Sungai Petani Community College, Kedah, Malaysia. A total of 74 data from 85 staff has been successfully gathered. According to [24], the number of data is sufficient as sample of respondents representing the entire population.

The questionnaires was developed in Malay language and was divided into five sections; a) demographic; b) management; c) organizational commitment; d) influence of peer group and e) readiness to change. There are 79 questions in the questionnaires which the answer period is estimated about 20 minutes. The study instrument used five Likert scale. Data collection is done through a staffs' monthly gathering. All staffs were required to answer the research instrument through the questionnaires given and the data gathered were analyse using the PLS-SEM 3.0 software.

\subsection{Data Analysis}


SPSS version 21 is used for descriptive statistic while for inferential statistic, PLS-SEM version 3.0 has been used to answer the research hypothesis. This study applied reflective measurement model and structural equation modelling in analysing the data.

\subsection{Descriptive Statistic}

Referring to the Table1.0 below which based on the 74 respondents indicated that 10 respondents (13.5\%) of the respondent's educational background were from Masters holders, 38 respondents (51.4\%) were degree holders, 11 respondents $(14.9 \%)$ were diploma holders and followed by 15 respondents from other certificates level $(20.3 \%)$.

Table 1: Highest Academic Achievement of Respondents

\begin{tabular}{|l|l|l|l|l|}
\hline $\begin{array}{l}\text { Academic } \\
\text { Achievement }\end{array}$ & Number & & $\begin{array}{c}\text { Perce } \\
\text { ntage }\end{array}$ \\
\hline \multirow{4}{*}{ Diploma } & 11 & & & 14.9 \\
\hline Degree & 38 & & & 51.4 \\
\hline Master & 10 & & & 13.5 \\
\hline Certificate & 15 & & & 20.3 \\
\hline Total & 74 & & & 100.0 \\
\hline
\end{tabular}

Table 2.0 below show the analysis of respondents' working experience. 4 respondents $(7.1 \%)$ have their working experience more than 15 years, while 9 respondents $(16.1 \%)$ have their working experience 13 to 15 years, whereas 16 respondents $(28.6 \%)$ have their working experience 9 to 12 years. 20 respondents (35.7\%) have their working experience 4 to 8 years and followed by 7 respondents $(12.5 \%)$ which their working experience ranging from 1 to 3 years. This shows that the College's staff has a diversity working experience that involve team work from junior and senior staffs.

Table 2: Working Experience of Respondents

\begin{tabular}{|c|c|c|}
\hline $\begin{array}{c}\text { Experience } \\
\text { (years) }\end{array}$ & Number & Percentage \\
\hline $1-3$ & 7 & 12.5 \\
\hline $4-8$ & 16 & 35.7 \\
\hline $9-12$ & 9 & 28.6 \\
\hline $13-15$ & 4 & 16.1 \\
\hline 15 \& above & 74 & 7.1 \\
\hline Total & & 100.0 \\
\hline
\end{tabular}

\subsection{Assessment of Measurement Models}

To measure the reliability and validity of the study, the model needs to go through the model fit process that consist of four analysis which are; a) Composite realibility; b) Convergent Validity; c) Construct Validity and; d) Convergent Validity which known as Confirmatory Factor Analysis (CFA). The purpose of doing CFA is to test whether the data gathered fit with hypothesized measurement model. Table 3 shows the report of the reliability and validity test through four variables.

Based on the table 3 below, five items were proposed in the instrument relating to the management and administration. The factor loadings of all the measured items are greater than 0.70 indicate that the convergent validity was obtained. The Composite Reliability is more than 0.6 which convincingly above the 
stipulated threshold level of acceptance reliability in compliance with [25]. AVE values were greater than 0.5 (0.922) which clearly posited that convergent validity is exist as suggested by [26]. and [27].

Six items were proposed in the instrument relating to Organizational Commitment. The factor loadings of all the measured items greater than 0.70 indicate that the convergent validity was obtained. In regards to reliability, the value of composite reliability is significantly higher than the minimum acceptable level of 0.60 as suggested by [25]. The AVE values were slightly than $0.5(0.579)$ which clarify that convergent validity is exist as suggested by [26] and [27].

Table 3: Model Measurement Evaluation

\begin{tabular}{|c|c|c|c|c|}
\hline $\begin{array}{c}\text { Latent } \\
\text { Variable }\end{array}$ & Indicator & Loading & $\begin{array}{l}\text { Composite } \\
\text { Relibility }\end{array}$ & AVE \\
\hline \multirow{5}{*}{$\begin{array}{l}\text { Management } \\
\& \\
\text { Administration }\end{array}$} & A1 & 0.790 & \multirow{5}{*}{0.986} & \multirow[t]{5}{*}{0.922} \\
\hline & A2 & 0.700 & & \\
\hline & A3 & 0.771 & & \\
\hline & A4 & 0.712 & & \\
\hline & A5 & 0.864 & & \\
\hline \multirow{6}{*}{$\begin{array}{l}\text { Organizational } \\
\text { Commitment }\end{array}$} & B1 & 0.720 & \multirow[t]{6}{*}{0.892} & \multirow[t]{6}{*}{0.579} \\
\hline & B2 & 0.720 & & \\
\hline & B3 & 0.762 & & \\
\hline & B4 & 0.772 & & \\
\hline & B5 & 0.822 & & \\
\hline & B6 & 0.766 & & \\
\hline \multirow{6}{*}{$\begin{array}{l}\text { Influence of } \\
\text { Peer group }\end{array}$} & $\mathrm{C} 1$ & 0.975 & \multirow[t]{6}{*}{0.878} & \multirow[t]{6}{*}{0.592} \\
\hline & $\mathrm{C} 2$ & 0.959 & & \\
\hline & C3 & 0.946 & & \\
\hline & $\mathrm{C} 4$ & 0.954 & & \\
\hline & $\mathrm{C} 5$ & 0.952 & & \\
\hline & C6 & 0.974 & & \\
\hline \multirow{18}{*}{$\begin{array}{l}\text { Readiness to } \\
\text { change }\end{array}$} & D1 & 0.957 & \multirow[t]{18}{*}{0.995} & \multirow[t]{18}{*}{0.920} \\
\hline & D2 & 0.943 & & \\
\hline & D3 & 0.926 & & \\
\hline & D4 & 0.957 & & \\
\hline & D5 & 0.940 & & \\
\hline & D6 & 0.962 & & \\
\hline & D7 & 0.979 & & \\
\hline & D8 & 0.939 & & \\
\hline & D9 & 0.942 & & \\
\hline & D10 & 0.920 & & \\
\hline & D11 & 0.962 & & \\
\hline & D12 & 0.983 & & \\
\hline & D13 & 0.971 & & \\
\hline & D14 & 0.984 & & \\
\hline & D15 & 0.970 & & \\
\hline & D16 & 0.976 & & \\
\hline & D17 & 0.974 & & \\
\hline & D18 & 0.974 & & \\
\hline
\end{tabular}

Similar process goes to the influence of peer group instruments consist of six items. The factor loadings are greater than 0.70 which indicates that the convergent validity was obtained. The value of composite reliability is also significantly higher than the minimum acceptable level of 0.60 as suggested by [25]. The AVE values were slightly than $0.5(0.592)$ which clarify that convergent validity is exist as suggested by [26] and [27]. 
The last instruments proposed is readiness to change which consist of eighteen items. The factor loadings onl the all measured items are greater than 0.70 which indicate that the convergent validity was obtained. For reliability, the value of composite reliability is significantly higher than the minimum acceptable level of 0.60 as suggested by [25]. The AVE values were greater than 0.5 (0.920) which clarify that convergent validity is exist as suggested by [26] and [27].

In sum, the values of the Goodness-of-Fit Indices for four instruments in measurement model is fit and with adequate data. This clearly indicates that the measurement model for management and administration, organizational commitment, influence of peer group and readiness to change exhibited strong evidence of unidimensionality, convergent validity and reliability. With this qualified, the second stage of the analytical process which is the path analysis can be carried out.

\subsection{Hypothesis Model Assessment}

In testing the significant and relevance of the relationship in the model, Bootstrapping procedure is used in the PLS-SEM software to see the relationship of independent variable and dependent variable in this hypothesis study. In estimating the path coefficients, the results were based on a significant $5 \%$ confidence level and T-value 1.96. The results illustrated in Table 4, indicated that only one of three path analysis were found to be significant.

Table 4: Path Analysis Result

\begin{tabular}{|c|c|c|c|c|}
\hline \multicolumn{2}{|c|}{ Path Analysis } & $\beta$ & $\begin{array}{c}\text { T } \\
\text { value }\end{array}$ & $\begin{array}{c}\text { P } \\
\text { Value }\end{array}$ \\
\hline H1 & $\begin{array}{l}\text { Peer Group Interaction -> } \\
\text { Readiness To Change }\end{array}$ & 0.478 & 5.303 & $\mathbf{0 . 0 0 0}$ \\
\hline $\mathbf{H 2}$ & $\begin{array}{l}\text { Organization Commitment } \\
->\text { Readiness To Change }\end{array}$ & 0.249 & 1.803 & 0.072 \\
\hline H3 & $\begin{array}{l}\text { Management \& } \\
\text { Administration -> } \\
\text { Readiness To Change }\end{array}$ & 0.207 & 1.349 & 0.178 \\
Note: *Significant at p<0.05 & & \\
\hline
\end{tabular}

The finding clearly indicates that Influence of peer group has a significant positive relationship with the employee's readiness to change $(\beta=0.478, \mathrm{t}=5.303, \mathrm{p}<.05)$. While the organization commitment $(\beta=$ $0.249, \mathrm{t}=1.803, \mathrm{p}=.072)$ and Management and Administration aspects $(\beta=0.207, \mathrm{t}=1.349, \mathrm{p}=.0 .178)$ show statistically insignificant. Based on the findings of the analysis above, Diagram 2 shows the final model of the study produced through the analysis procedure of Partial Least Squares Structural Equation Modelling (PLS-SEM) version 3 system. 


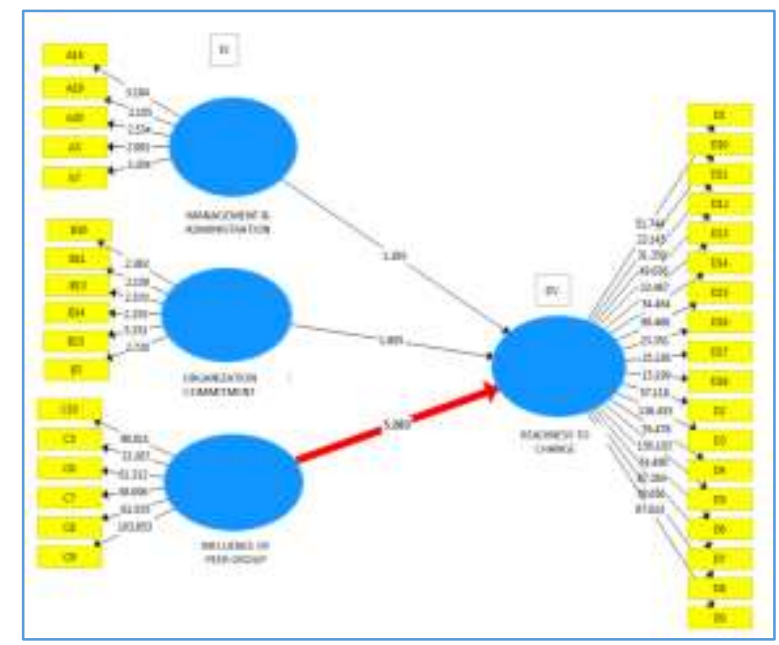

Diagram 2: Path Analysis

\subsection{Discussion, Recommendation and Conclusion}

The purpose of this study is to identify variables or contributing factors to the staff readiness to change at the Sungai Petani Community College, Kedah. There are three factors or independent variables in the proposed model. The variables used are administrative and management, organizational commitment and influence of peer group.

As a result of the analysis, influence of peer group have been identified as a main contributor factor to Sungai Petani Community College staff in their readiness to change. Their willingness to do something is because of the friendliness, familiarity and comfort working together among each other in their daily work. In addition, the challenge rivalry in accomplishing work tasks will make their relationship becomes negative.

Due to the work pressure that cause the employees' conflict, they will always maintain a relationship while working and socializing together. Staffs in the SPCC are also seen to have a high level of loyalty at the work place. They acknowledged that in their career development, they will try to ensure to work together in achieving the organizational goal. Togetherness in accomplishing tasks becomes a nature in their work culture. The loyalty and responsibility to the college are still a main priority in carrying out their task.

Management and administration factors and organizational commitment are seen to have little impact on staff readiness to change. This may due to the approaches are less conducive or delivery of information on organization changes are not well understood by the staffs.

Some suggestions were identified based on the findings of this study. This influence of peer group factor can be further enhanced by providing social enthusiast and social communication programs so that the staff relationship can be further enhanced. Influence of peer groups can give an impact to other staffs to change. This is the most persuasive agent of changes for the organization. The management of the organization will become stronger if the manpower is strong and united.

The Management of the the Sungai Petani Community College, Kedah also need to re-evaluate the effectiveness of the information channel used to deliver the information and also ensure how fast the information on the organizational changes can be reached to the employees. The awareness on organizational changes needs to be given and the justification for a changes should be delivered through the 
right medium communication such as courses and training. The alignment in delivering information through level of knowledge and understanding between staffs should be emphasized so that staffs can understand and know their function in the organization.

In conclusion, the strength of a peer group within the Sungai Petani Community College staff had played a significant role in determining the success and assisting in the organizational changes. This factor is a key element in the success of change in the organization.

\section{References}

[1] Kiprop, C. R. (Issue2, Vol. 2 (March-2012)). Motivational Strategies For Public Sector Workers in Kenya. International Journal of Research in Management, Vol. 2(Issue 2), 71-86.

[2] Owoyemi, O., \& Ekwoaba, J. (2014). Organisational Culture: A Tool for Management to Control, Motivate and Enhance Employees' Performance. American Journal of Business and Management, Vol. 3(3), 168-177.

[3] Najafi, S., Noruzy, A., Azar, H. K., Shirkouhi, S. N., \& Dalvand, M. R. (2011). Investigating the relationship between organizational justice, psychological empowerment, job satisfaction organizational commitment and organizational citizenship behavior: An empirical model. African Journal of Business Management, Vol.5 (13), 5241-5248.

[4] Chew, M. M., Cheng, J. S., \& Lazarevic, S. P. (2006). Managers' Role In Implementing Organizational Change: Case Of The Restaurant Industry In Melbourne. Journal of Global Business and Technology, Volume 2(1), 58-67.

[5] Soparnot, R. (2011). The Concept of Organizational Change Capacity. Journal of Organizational Change Management, 24(5), 640-661. http://dx.doi.org/10.1108/09534811111158903

[6] Banks, B. C. (2010). Managing change and transitions:a comparison of different models and their commonalities. Emerald Insight, Vol. 31 ( 4/5), 241-252.

[7] Ilgen, D. R. \& Pulakos, E. D. (1999). Employee performance in today's organizations. In D. R. Ilgen \& E. D.Pulakos (Eds.), The changing nature of performance: Implications for staffing, motivation, and development: 21-55. San Francisco: Jossey-Bass

[8] Robbins, S. P. (2001). Organizational Behavior. New Jersey: Prentice Hall.

[9] Madsen, S., Miller, D., \& John, C. (2005). Readiness for Organizational Change: Do OrganizationalCommitment and Social Relationships in the Workplace Make a difference? Human Resource Development Quarterly, 16(2), 213-234. http://dx.doi.org/10.1002/hrdq.1134

[10] Weiner, B. (2009). A Theory of Organizational Readiness for Change. Implementation Science 4:67

[11] Smollan, R. (2011). Engaging with Resistance to Change. Business Review, 13 (1), ss. 12-15.

[12] Blackman, D., O’Flynn, J., \& Ugyel, L. (2013). . (2013) “A Diagnostic Tool for Assessing Organisational Readiness for Complex Change. Australian and New Zealand Academy of Management (ss. 1-18). Hobart: Australian and New Zealand Academy of Management.

[13] Choi, M. (2011). Employees Attitudes toward Organizational Change: A Literature Review, Human Resource Management, Vol. 50, No. 4, Pp. 479 -500.

[14] Melchar, D. E., Bosco, S. M. (2010). Achieving high organization performance through servant leadership. Journal of Business Inquiry: Research, Education \& Application, 9, 74-88 
[15] Brummelhuis, L. T. (2012). The relationship between servant leadership, quality of communication, change readiness and successful change. Unpublished Master Thesis, University of Groningen, Groningen, Netherlands.

[16] Mohamad, M., Don, Y., \& Ismail, S. N. (2016). Kepimpinan strategik dan hubungannya dengan kesediaan perubahan warga organisasi. Jurnal Kepimpinan Pendidikan, 3(2), 1-14

[17] Slocum, J. W. \& Hellriegel, D. (2007). Fundamentals of Organizational Behaviour. USA: Thomson South Western.

[18]Chen, K., and O’Mahony, S. (2009). "Differentiating Organizational Boundaries.” In Michael Lounsbury (ed.), Research in the Sociology of Organizations, No 26, 183-220.

[19]Dehghan, F. \& Saeidi, P. (2013). Investigating the relationship between emotional intelligence and organizational commitment. Unique Journal of Business management Research, 1(5), 81-94

[20] Somech, A., \& Bogler, R. (2002). Antecedents and consequences of teacher organizational and professional commitment. Educational Administration Quarterly, 38(4), 555-577.

[21] Mancini, B. A. (2008). The relationship of transformational and transactional leadership to job satisfaction and organizational commitment within for-profit organizations on Long Island, New York.(3312894 Ed.D.), Dowling College, Ann Arbor. Retrieved from https://vpn.utm.my/docview/304820272?accountid=41678 ProQuest Central; ProQuest Dissertations $\&$ Theses Global database.

[22]Clark, R. E. (2003). Fostering the Work Motivation of Individuals and Teams. Performance Improvement, 42(3), 21-29.

[23] Vorgelegt, v. (2004). Organizational Change:Formulating, Implementing, and Sustaining a Fundamental Organizational Change in South American Central Banks Pilot Study Colombia. Germany.

[24]Krejcie, R.V., \& Morgan, D.W. (1970). Determining sample size for research activities. Educational and Psychological Measurement, 30, 607-610.

[25]Hair, Joseph F., G. Tomas M. Hult, Christian M. Ringle, and Marko Sarstedt. (2016). A Primer on Partial Least Squares Structural Equation Modeling (PLS-SEM). 2nd edition, Thousand Oaks: Sage.http://www.pls-sem.com

[26]Chin, W. W. 1998. "The partial least squares approach to structural equation modeling," In Modern methods for business research, G. A. Marcoulides (ed.), Mahwah, NJ: Lawrence Erlbaum Associates Publishers, pp. 295-336.

[27]Ringle, C. M., Wende, S. and Becker, J. M. (2014). Smartpls3. Hamburg: SmartPLS 